This article is licensed under the Creative Commons Attribution-NonCommercial 4.0 International License (CC BY-NC) (http://www.karger.com/Services/OpenAccessLicense). Usage and distribution for commercial purposes requires written permission.

\title{
Idiopathic Pan-Colonic and Small-Intestine Varices
}

\author{
Peter Liptak Martin Schnierer Peter Banovcin Jr. Martin Duricek \\ Rudolf Hyrdel \\ Comenius University in Bratislava, Jessenius Faculty of Medicine in Martin (JFM CU), \\ Gastroenterology Clinic JFM CU, Martin, Slovakia
}

\section{Keywords}

Varices $\cdot$ Idiopathic colonic varices $\cdot$ Colon $\cdot$ Ileum $\cdot$ Haemorrhage

\begin{abstract}
Idiopathic colonic varices represent a rare source of gastrointestinal haemorrhage with a presumed incidence around $0.0007 \%$. Herein, we present a case of idiopathic colonic and smallintestine varices. According to our knowledge, this case report is the first description of both pan-colonic and small-intestine idiopathic varices of this extent. A young male patient without any previous notable medical history was admitted to the hospital because of massive enterorrhagia with haemodynamic instability. Colonoscopy revealed massive pan-colonic varices. After stabilization, numerous diagnostic procedures were performed in order to investigate the aetiology of pan-colonic varices without any explanation of the patient's condition. In addition, capsule endoscopy revealed varices through the whole length of the small intestine. The final diagnosis was idiopathic varices of the colon and small intestine. Because of the rapid clinical stabilization, the single incident of haemorrhage and the extension of the disease, a conservative approach was chosen (venotonics and $\beta$-blockers). During the 12 -month followup period, the patient reported no gastrointestinal haemorrhage.
\end{abstract}




\section{Case Reports in Gastroenterology}

Case Rep Gastroenterol 2018;12:757-764

DOI: $10.1159 / 000495602$

(C) 2018 The Author(s). Published by S. Karger AG, Basel www.karger.com/crg

Liptak et al.: Idiopathic Pan-Colonic and Small-Intestine Varices

\section{Introduction}

Colon varices represent a rare source of severe lower gastrointestinal haemorrhage and have a prevalence rate of around $0.07 \%$ [1]. This condition is usually associated with portal hypertension. Idiopathic varices are substantially rarer. A review of sources in the literature revealed that only around 40 cases of idiopathic colonic varices have been reported up to this date [2]. Varices occur mostly only in some segments of the colon. Herein, we describe the first known case of pan-colonic idiopathic varices with involvement of the whole small intestine.

\section{Case Report}

A 31-year-old male patient presented without any notable past medical history and without any surgery in the abdominal region. The patient had no previous episodes of haemorrhage from the gastrointestinal tract.

He was admitted to a local hospital due to massive enterorrhagia with haemodynamic instability. After initial conservative treatment, the patient remained clinically stable and was transferred to the Clinic of Gastroenterological Internal Medicine UHM and JFM CU for further evaluation and treatment.

Upon admission to the Clinic of Gastroenterological Internal Medicine, the patient was clinically stable (blood pressure: 130/78 $\mathrm{mm} \mathrm{Hg}$, heart rate: 70/min, oxygen saturation of peripheral blood: $98 \%$, body temperature: $36.5^{\circ} \mathrm{C}$ ), and no signs of haemorrhage were present. His body height was $192 \mathrm{~cm}$ and body weight was $80 \mathrm{~kg}$ (BMI 21.7). Physical examination revealed no pathological signs. The abdominal region was without palpable masses and without tenderness. Haemoglobin level was $97 \mathrm{~g} / \mathrm{L}$, haematocrit 0.28 and white blood cell count $2.8 \times 10^{9} / \mathrm{L}$. Coagulation parameters (international normalized ratio and activated partial thromboplastin time) were normal (Table 1). Liver function tests showed normal values (Table 1), and autoimmune and metabolic liver diseases were excluded. Levels of ceruloplasmin $(0.2 \mathrm{~g} / \mathrm{L})$ and $\alpha$-1-antitrypsin $(1.57 \mathrm{~g} / \mathrm{L})$ were within normal ranges (reference range: $0.2-0.6$ $\mathrm{g} / \mathrm{L}$ for ceruloplasmin, $0.89-2.05 \mathrm{~g} / \mathrm{L}$ for $\alpha$-1-antitrypsin). Serological tests including EpsteinBarr virus, cytomegalovirus and hepatitis A, B and C were negative. Tumour markers $\alpha-1$-fetoprotein (AFP) (4.06 $\mu \mathrm{g} / \mathrm{L})$, carcinoembryonic antigen (CEA) $(0.71 \mu \mathrm{g} / \mathrm{L})$ and carbohydrate antigen 19-9 (CA 19-9) (11.33 kU/L) were within normal ranges (reference range: 0-9.0 $\mu \mathrm{g} / \mathrm{L}$ for AFP, 0-3.4 $\mu \mathrm{g} / \mathrm{L}$ for CEA and 0-35 kU/L for CA 19-9). Albumin level was $40.2 \mathrm{~g} / \mathrm{L}$ (reference range: $35-52 \mathrm{~g} / \mathrm{L})$. Glucose $(4.6 \mathrm{mmol} / \mathrm{L})$ and creatinine $(94 \mu \mathrm{mol} / \mathrm{L})$ levels were normal (Table 1).

Colonoscopy immediately after admission revealed extensive varices in the whole colon and terminal ileum with stigmata of possible imminent haemorrhage. Doppler sonography of the hepatic circulation showed hepatic veins with a normal diameter, without thrombosis. The maximum diameter of the portal vein was $12 \mathrm{~mm}$, blood flow velocity was $17.5 \mathrm{~cm} / \mathrm{s}$, with the same direction of flow as in the arteria hepatica propria. That means that Doppler ultrasonography of the hepatic circulation showed normal findings. Gastroduodenoscopy to D3 part of the duodenum showed no pathomorphological changes.

Computed tomography (CT) with 3-phase angiography was performed, and no signs of portal hypertension and thrombosis in the splanchnic veins were present. Varicose changes 


\section{Case Reports in Gastroenterology}

Case Rep Gastroenterol 2018;12:757-764

DOI: $10.1159 / 000495602$

(c) 2018 The Author(s). Published by S. Karger AG, Base www.karger.com/crg

Liptak et al.: Idiopathic Pan-Colonic and Small-Intestine Varices

in the branches of the superior mesenteric vein in the left epi- and mesogastrium were visualized. The signs of varices in the jejunum wall (Fig. 1), ileum (Fig. 2) and colon (Fig. 3) were present. Digital selective angiography showed no signs of arteriovenous malformations of the splanchnic circulation. Capsule endoscopy confirmed our previous findings, and varicosities in the whole small intestine, with a maximum in the ileum, were identified (Fig. 4). Based on all these findings, any causes of varices in the small intestine and colon due to changes in the magistral splanchnic blood vessels were excluded.

Thrombophilia was excluded as well. Genetic analysis showed no mutations of MTHFR C667T, A1298C or factor V Leiden.

During admission, the patient had no episodes of haemorrhage from the gastrointestinal tract and anaemisation. Therefore, a conservative approach with long-term medication consisting of venotonics and a small dose of $\beta$-blockers (carvedilol $12.5 \mathrm{mg}$ twice per day) was chosen. The patient reported no gastrointestinal haemorrhage during his 12-month follow-up period.

\section{Discussion}

Colonic varices represent a very rare cause of lower gastrointestinal haemorrhage. Colon varices usually occur as a result of portal hypertension due to changes of the liver parenchyma (e.g., in cirrhosis, hepatocellular carcinoma, etc.). In the presented case, a parasitic liver infection was excluded although the patient came from an endemic area [3].

Another common cause of portal hypertension and, therefore, colon varices could be thrombosis of the portal vein. Patients with myeloproliferative diseases, antiphospholipid syndrome, protein $\mathrm{C}$ and protein $\mathrm{S}$ deficiency, antithrombin III deficiency or mutation of factor $\mathrm{V}$ Leiden are at a higher risk of portal vein occlusion [1].

Idiopathic colonic varices represent an extremely rare condition. According to our knowledge, only around 40 cases have been reported up to now [2]. Based on the findings in autoptic materials, the incidence is around $0.0007 \%$, but the prevalence is supposed to be slightly higher due to disease manifestation being not always clear [4]. Idiopathic colon varices could manifest by haematochezia or small lower gastrointestinal haemorrhage in some of the cases. Men are more likely to be affected by this condition than women, and the mean age at diagnosis is 41.3 years [5]. It is important to point out that colonic varices as a secondary result of portal hypertension rarely extend beyond the anorectal area, in contrast to colonic varices with an idiopathic cause. Approximately in half of the idiopathic cases, varices extending to the whole colon have been reported [6]. One third of the reported cases have a familiar origin [5]. The partially familiar character of this disease (excluded in our patient) suggests a possible relationship with connective tissue diseases [7].

Another possible aetiological factor for colon varices could be arteriovenous malformations in the splanchnic region. Selective angiography is a reliable method to investigate the venous system in the desired area and, therefore, can represent a valuable tool in the differential diagnosis of colon varices in order to determine the extension and/or aetiology of the disease [8].

Endoscopy plays an indisputably superior role in the differential diagnosis of gastrointestinal haemorrhage in general. On the other hand, the risk of colonoscopy in this case lies in a 
possible collapse of varices after the inflation of the intestine and, therefore, presents the possibility for misdiagnosis. Varices can also have the visual characteristics of polyps, malignancy or ulcerative colitis [9]. A biopsy performed from these suspicious areas could lead to massive, potentially fatal haemorrhage [9].

Another crucial examination modality is CT with angiography. Especially in the case of colon varices, this method plays a pivotal role in the diagnostic process. As a final diagnostic method to determine the extension and to visualize the condition of the gastrointestinal tract, capsule endoscopy was performed. Capsule endoscopy as a method is useful and effective and ensures patient comfort during the diagnostic process [10].

Idiopathic colonic varices represent a rare cause of gastrointestinal bleeding. Management of this condition is individual and can vary greatly according to the clinical presentation and actual condition of the patient $[1,5,7]$. Patients with recurrent massive and haemodynamically unstable haemorrhage require surgery with partial resection of the affected intestinal segment [7]. In our case, a conservative approach was decided on due to a single episode of enterorrhagia, stability during the observation period and extensive occurrence of varices. In general, patients with idiopathic colonic varices have a better prognostic survival rate than patients with secondary colonic varices related to portal hypertension [7].

\section{Statement of Ethics}

The authors have no ethical conflicts to disclose.

\section{Disclosure Statement}

The authors have no conflicts of interest to declare.

\section{References}

1 Dina I, Braticevici CF. Idiopathic colonic varices: case report and review of literature. Hepat Mon. 2014 Jul;14(7):e18916.

2 Sunkara T, Caughey ME, Culliford A, Gaduputi V. Idiopathic Isolated Colonic Varices: An Extremely Rare Condition. J Clin Med Res. 2018 Jan;10(1):63-5.

3 Šimeková K, Szilágyiová M, Antolová D, Laca L’, Polaček H, Nováková E, et al. Contribution to the Diagnosis and Treatment of Life-Threatening Parasitosis Caused by the Parasite Echinococcus multilocularis. Vector Borne Zoonotic Dis. 2017 Apr;17(4):225-8.

4 Peixoto A, Silva M, Pereira P, Macedo G. Giant idiopathic pancolonic varices - a rare entity. Clin Res Hepatol Gastroenterol. 2016 Jun;40(3):255-6.

5 Francois F, Tadros C, Diehl D. Pan-colonic varices and idiopathic portal hypertension. J Gastrointestin Liver Dis. 2007 Sep;16(3):325-8.

6 Place RJ. Idiopathic colonic varices as a cause of lower gastrointestinal bleeding. South Med J. 2000 Nov;93(11):1112-4.

7 Iredale JP, Ridings P, McGinn FP, Arthur MJ. Familial and idiopathic colonic varices: an unusual cause of lower gastrointestinal haemorrhage. Gut. 1992 Sep;33(9):1285-8.

8 Nikolopoulos N, Xynos E, Datsakis K, Kasapidis P, Vassilakis JS. Varicosis coli totalis: report of a case of idiopathic aetiology. Digestion. 1990;47(4):232-5. 


\section{Case Reports in Gastroenterology}

\begin{tabular}{l|l}
\hline Case Rep Gastroenterol 2018;12:757-764 \\
\hline DOI: 10.1159/000495602 & $\begin{array}{l}\text { @ 2018 The Author(s). Published by S. Karger AG, Basel } \\
\text { www.karger.com/crg }\end{array}$ \\
\hline
\end{tabular}

Liptak et al.: Idiopathic Pan-Colonic and Small-Intestine Varices

9 Vescia FG, Babb RR. Colonic varices: a rare, but important cause of gastrointestinal hemorrhage. J Clin Gastroenterol. 1985 Feb;7(1):63-5.

10 Tang SJ, Zanati S, Dubcenco E, Cirocco M, Christodoulou D, Kandel G, et al. Diagnosis of small-bowel varices by capsule endoscopy. Gastrointest Endosc. 2004 Jul;60(1):129-35.

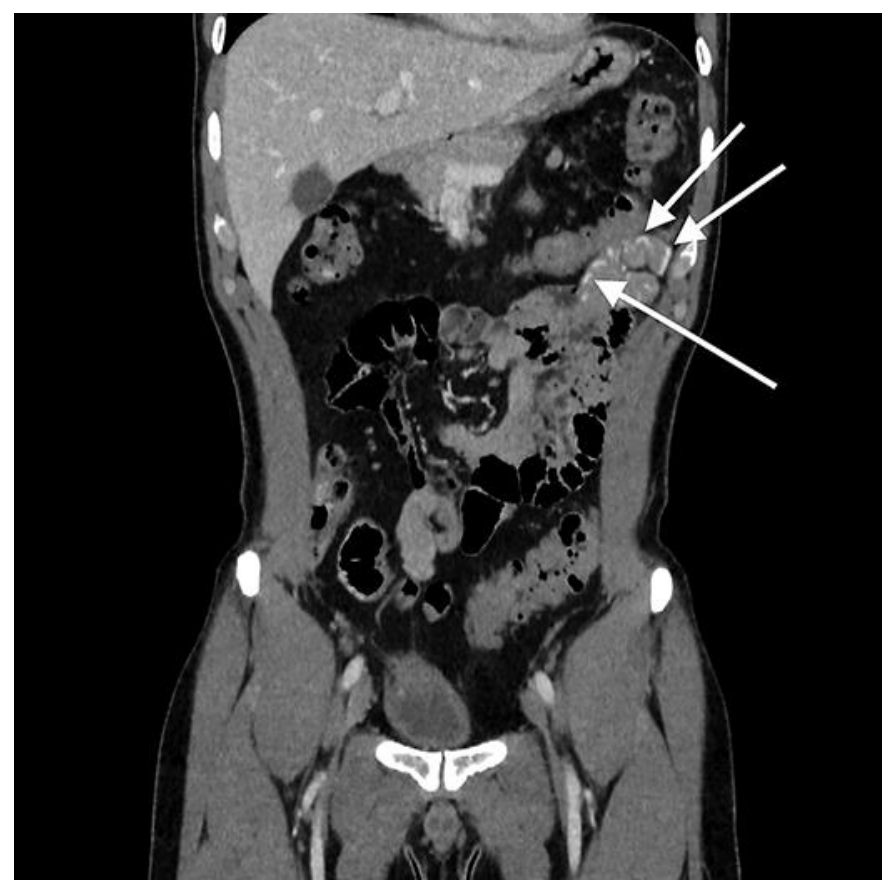

Fig. 1. CT with 3-phase angiography. The white areas represent varices in the jejunum (arrows). 


\section{Case Reports in Gastroenterology}

Case Rep Gastroenterol 2018;12:757-764

(C) 2018 The Author(s). Published by S. Karger AG, Basel www.karger.com/crg

Liptak et al.: Idiopathic Pan-Colonic and Small-Intestine Varices

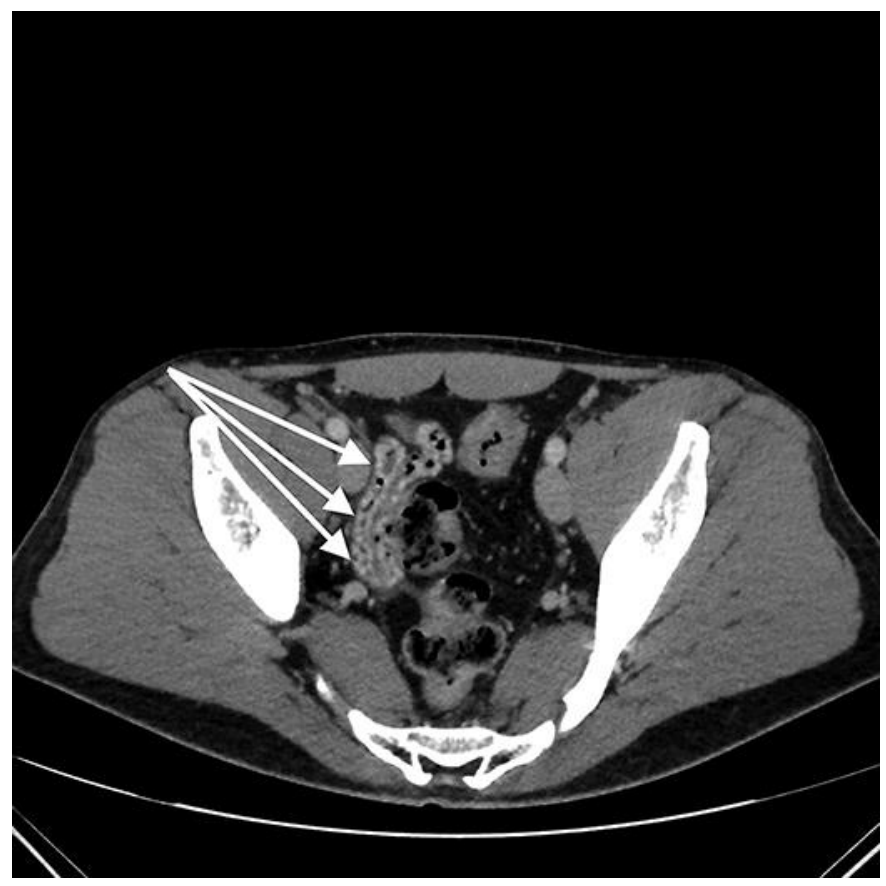

Fig. 2. CT with 3-phase angiography. The white areas represent varices in the ileum (arrows). 


\section{Case Reports in Gastroenterology \\ Case Rep Gastroenterol 2018;12:757-764

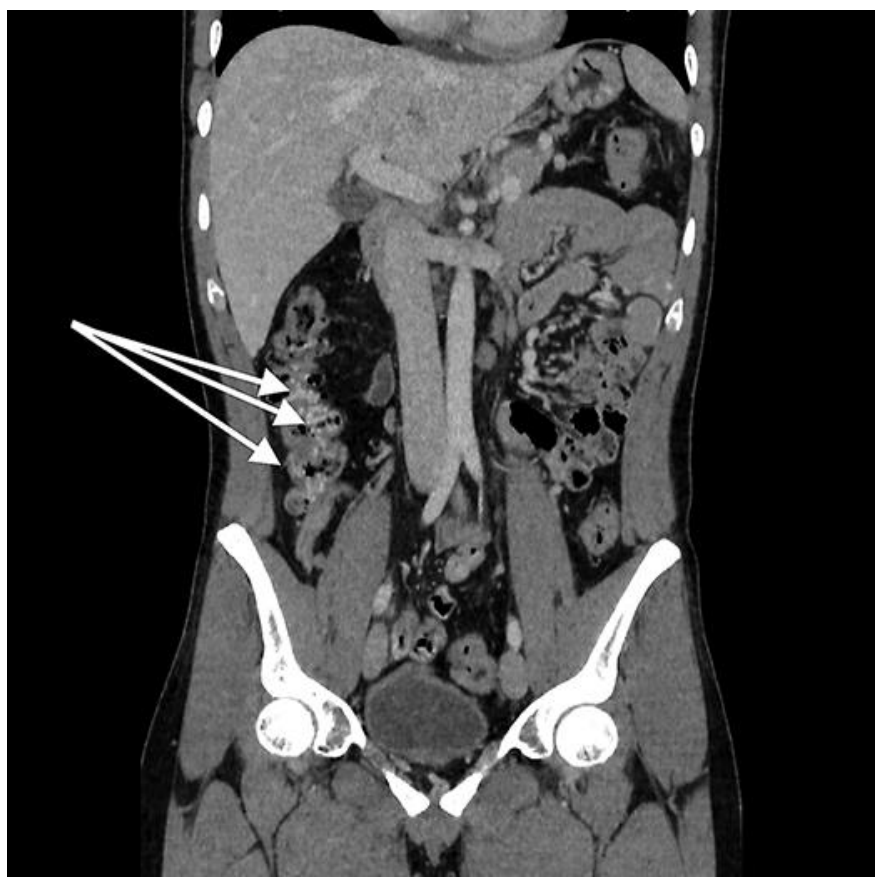

Fig. 3. CT with 3-phase angiography. The white areas represent varices in the colon ascendens and cecum (arrows).

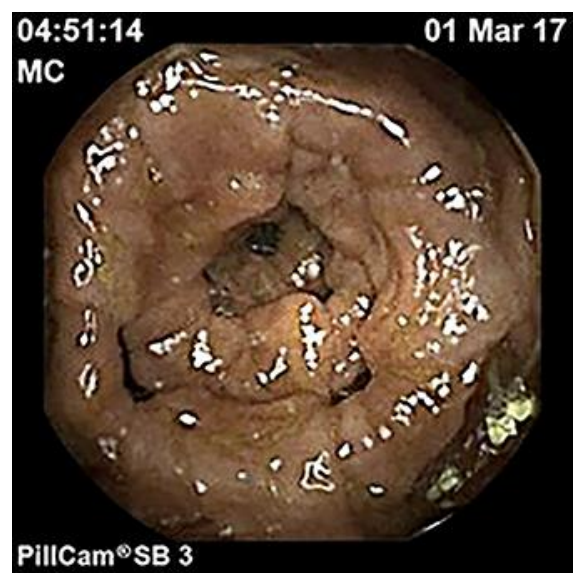

Fig. 4. Varices visible in the ileum during capsule endoscopy. 
Liptak et al.: Idiopathic Pan-Colonic and Small-Intestine Varices

Table 1. Laboratory findings upon admission and at the end of hospitalisation

\begin{tabular}{lccc}
\hline Laboratory parameters & Reference & Admission & $\begin{array}{c}\text { End of } \\
\text { hospitalisation }\end{array}$ \\
\hline Haemoglobin, g/L & $140-179$ & 97 & 109 \\
White blood cell count, cells/L & $3.9-10 \times 10^{9}$ & $2.8 \times 10^{9}$ & $4.3 \times 10^{9}$ \\
Platelet count, cells/L & $140-400 \times 10^{9}$ & $182 \times 10^{9}$ & $267 \times 10^{9}$ \\
Haematocrit, \% & $0.39-0.54$ & 0.28 & 0.33 \\
APTT, s & $22-32$ & 31.0 & 25.5 \\
INR & $0.8-1.2$ & 0.96 & 1.03 \\
Total bilirubin, $\mu$ mol/L & $5-21$ & 5.6 \\
GMT, $\mu$ kat/L & $0.03-0.92$ & 9.7 & 0.28 \\
ALP, $\mu$ kat/L & $0.5-2.0$ & 0.2 & 0.77 \\
AST, $\mu$ kat/L & $0.1-0.85$ & 0.74 & 0.22 \\
ALT, $\mu \mathrm{kat} / \mathrm{L}$ & $0.1-0.85$ & 0.3 & 0.19 \\
CRP, mg/L & $0-5$ & 0.27 & 1.2 \\
Albumin, g/L & $35-52$ & 0.6 & - \\
Creatinine, $\mu \mathrm{mol} / \mathrm{L}$ & $74-110$ & 40.2 & 92 \\
Urea, mmol/L & $2.8-7.2$ & 94 & 4.3 \\
Glucose, mmol/L & $4.1-5.9$ & 4.5 & 4.5 \\
Sodium, mmol/L & $135-146$ & 4.6 & 142 \\
Potassium, mmol/L & $3.5-5.1$ & 138 & 4.8 \\
Chloride, mmol/L & $101-109$ & 4.0 & 106 \\
\end{tabular}

APTT, activated partial thromboplastin time; INR, international normalized ratio; GMT, gamma-glutamyl transferase; ALP, alkaline phosphatase; AST, aspartate aminotransferase; ALT, alanine aminotransferase; CRP, C-reactive protein. 